96

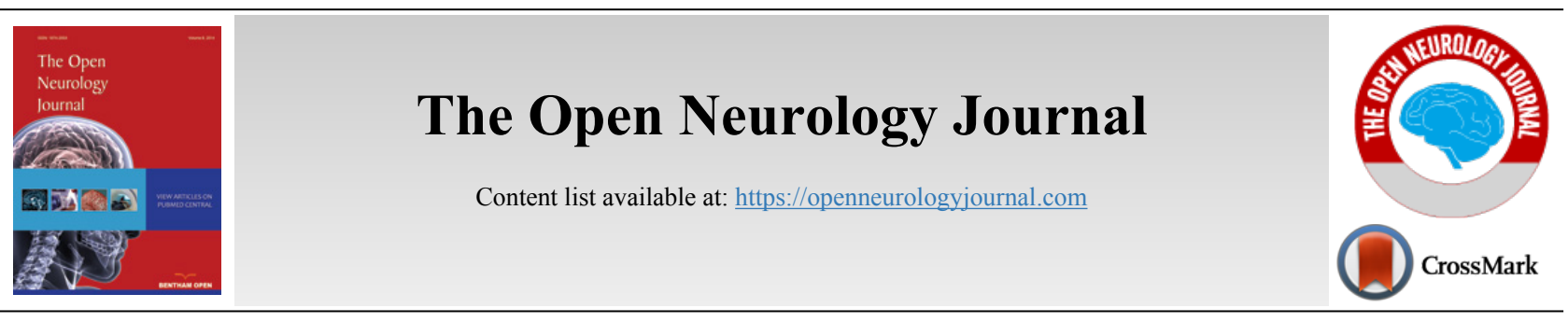

SYSTEMATIC REVIEW

\title{
Surgical Robotic Technology for Developing an Endonasal Endoscopic Transsphenoidal Surgery (EETS) Robotic System
}

\author{
Sorayouth Chumnanvej ${ }^{1}$, Branesh M. Pillai ${ }^{2}$ and Jackrit Suthakorn ${ }^{2, *}$ \\ ${ }^{\prime}$ Neurosurgery Division, Department of Surgery, Faculty of Medicine Ramathibodi Hospital, Mahidol University, Bangkok, Thailand \\ ${ }^{2}$ Center for Biomedical and Robotics Technology (BART LAB) Department of Biomedical Engineering, Faculty of Engineering, Mahidol University, \\ Salaya, Thailand
}

\begin{abstract}
:
Purpose:

Neurosurgical robots are acknowledged for their advantages in assisting neurosurgeons in enhancing their precision and accuracy. Here, the aim of this study is to report the first use as a robot-assisted Endonasal Endoscopic Transsphenoidal (EET) approach, applied to reach sphenoid sinus in a cadaver. The introduction of the seven tenets for the Endonasal Endoscopic Transsphenoidal approach will propel the feasibility of neurosurgical techniques and instruments for intrasellar lesions

Methods:

Endonasal endoscopic transsphenoidal approach in a cadaver was performed under robot assistance with simple navigation system. This preliminary study reveals the accuracy and precision of the robot to reach a target at sphenoid sinus safely and within the shortest duration

Results:

This robotic technology provided the foundation to support neurosurgeons when they are working in narrow and complicated surgical corridors with accuracy and precision.

Conclusion:

This article reveals the first robot-assisted Endonasal Endoscopic Transsphenoidal approach. This demonstrates the feasibility of the evolution and will augment neurosurgeons toward their limits of minimally invasive surgical techniques, manual dexterity, and spatial orientation. These tenets will be as state of the art and overcome the future challenges of Endonasal Endoscopic Transsphenoidal approach shortly.
\end{abstract}

Keywords: Endoscopic Endonasal Transphenoid (EET), Medical robotics, Minimally invasive surgery, Neurosurgical robots, Pituitary adenoma Robotic surgery.

Article Histor

Received: April 01,2019

Revised: June 20,2019

Accepted: June 24, 2019

\section{INTRODUCTION}

\subsection{New and Upcoming Technological Advances in the Medical Field}

The field of medical imaging technology is growing fast, and the enormity of changes in the area is hard to fathom. Mobile application based medical imaging and Internet of Things (IoT) is blooming in the medical imaging arena and is

\footnotetext{
* Address correspondence to this author at the Center for Biomedical and Robotics Technology (BART LAB), Department of Biomedical Engineering, Faculty of Engineering, Mahidol University, Salaya, Thailand; ORCID id: 0000-0003-1333-3982; Tel: +662-441-4255; Fax: +662-441-4254;

E-mails: jackrit@bartlab.org, jackrit.sut@mahidol.ac.th
}

routinely used cases like 3D viewing, and Picture Archiving and Communication System (PACS) connectivity [1, 2]. Recently, big data analytics has caught attention in the medical imaging field for its exceptional contribution to the care continuum and for the maintenance of Electronic Health Record (EHR) data [3]. The personalized medicine got modernized only after the $1950 \mathrm{~s}$. With the introduction of first automated and programmable computational machines (Fig. 1), neurosurgery field progressed rapidly and resulted in the development of modern computers.

With the advancement of database based data collection and introduction of the modern computer, large data set management during clinical trial just got better. A comparison 
between conventional paper-based data collection and computer interface data collection is outlined (Fig. 2).

Development and utilization of robots in medical imaging is another potential area of technologic growth [4]. Use of Robots in the neurosurgery field is not a new concept. However, they are less commonly used compared to the extent they are used in other medical areas. When a surgeon reaches the human limits of precision of motor function, robotic devices help in stabilizing physiologic tremor and minimize the invasiveness of a surgical procedure.

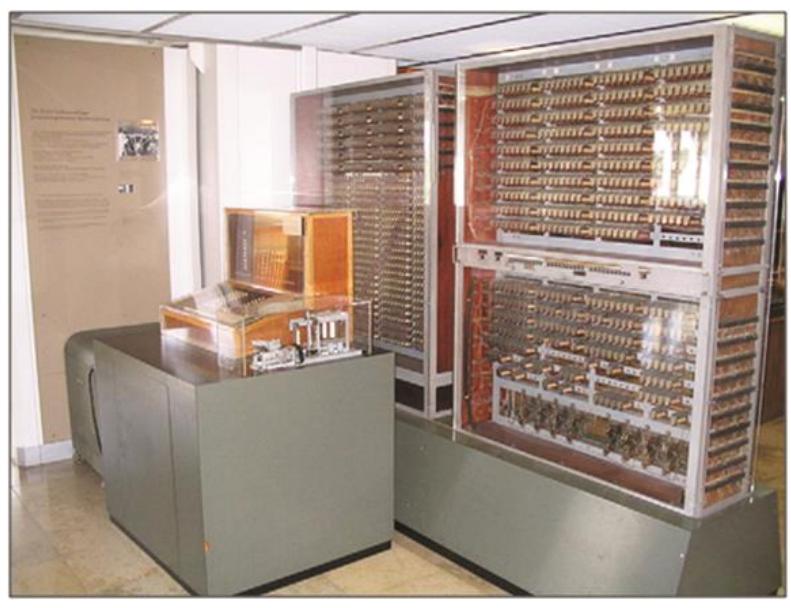

Fig. (1). The Zuse Z3- world's first operational computer designed by Konrad Zuse in 1941. (Original image courtesy: Venusianer.).

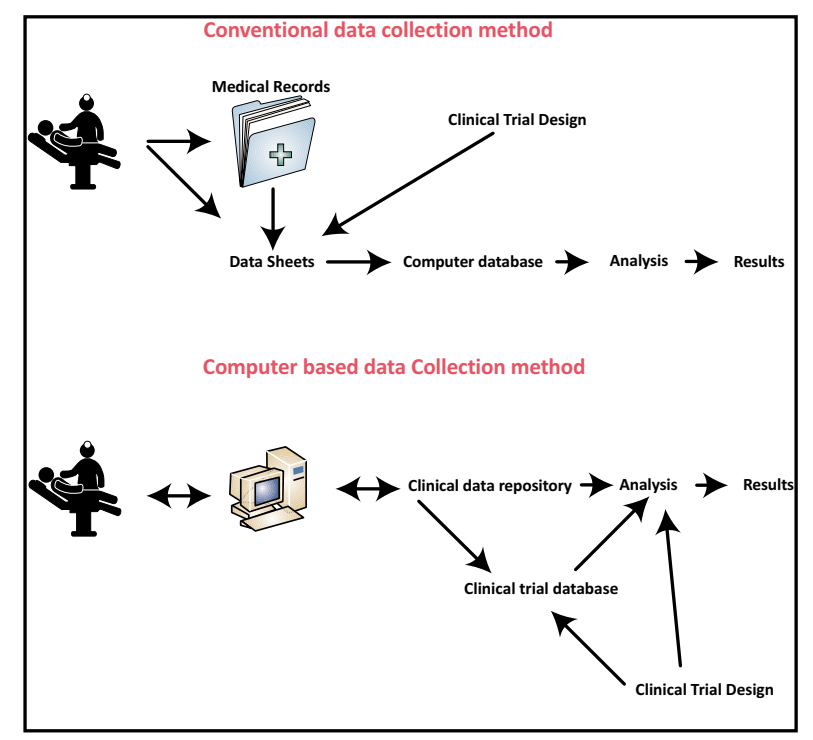

Fig. (2). Conventional paper based data collection method versus computer interface data collection method during a clinical trial period.

\subsection{Medical Robotics}

Crucial advances in computer technology are also potentially providing the opportunity for minimally invasive procedures. Based on the development of the rapidly growing computer technology platform, there are feasibilities to generate several accurate and precise neurosurgical procedures under experienced neurosurgeons. However, human error is still alarming in this field. Additionally, the quality improvements (QI) in engineering industrial applications of robotics have enthused. These QI applications not only work for the present technology but can also be applied in the minimally invasive neurosurgical area. The advantages of the robotic applications over the human works include high precision, high accuracy, reliability, and repetition of the process, no exhaustion and no hand trembling. Practicing, working in surgery and ergonomics studies demonstrated that muscle fatigue occurs due to the long-time procedures and the position of surgical instruments [5 - 8]. So, the drawbacks of surgery by a human being include the possibility of inaccuracy and mismanagement. The visualization, manipulation, posture, mental and physical workload and environment are the factors that play a key role in restricting the neurosurgeons' capabilities [8]. Several robotic systems were developed and exercised in neurosurgery regarding a patient's safety with ethical concerns. The neurosurgical robots have been invented for clinical practice while some others still have been in the research. Even though robotic surgery is getting more attention in the last decades, there are still a few limitations associated with the procedure. Not all minimally invasive procedures can be reached out with a robot. Also, not all medical cases are appropriate for robotic surgery. The traditional endoscopic or open surgery is still the preferred option in many surgical cases [9]. Some of the more common procedures that use robotic surgical technique include (a) Cardiovascular surgery, (b) Head and neck surgery, (c) Gynaecologic surgery, (d) Partial knee replacement surgery, (e) Abdominal, colon and rectal surgery, (f) Urologic surgery and more recently (g) Neurosurgery [9].

\subsection{Endoscopic Endonasal Transsphenoid Technique in Neurosurgery}

While focusing on the several different techniques in neurosurgery that offer "minimal invasion" during the surgical procedure, Endoscopic Endonasal Transphenoid (EET) technique is widely used by neurosurgeons and otolaryngologists [10]. This method provides minimally invasive access to the anterior cranial base and substitute's endoscopic technology in resecting part or the entire tumor in the sellar region. Like any other endoscopic technique, EET comes with its pros and cons. The scope positioned within the nostril or sphenoid sinus, blood and other bodily fluids easily clouds the lens and interferes with the surgical procedure. Also, the magnification factor and optical quality of the microscope are slightly superior to that of endoscopes, even though the difference is nominal in the majority of procedures and more than compensated for the improved degree of visualization and dexterity the endoscope provided the surgeon. Also, though the endoscopy is two-dimensional and most neurosurgeons are familiar with the typical stereoscopic vision of the microscopes, the EET is rapidly adopted by the surgeons [11]. Irrespective of the valid limitations of endoscopy (not a costeffective technology, longer operative time, number of surgeons required is more than conventional microscopy approach), it compensates by the multitude of advantages that offers during the transsphenoidal surgery [11]. However, there 


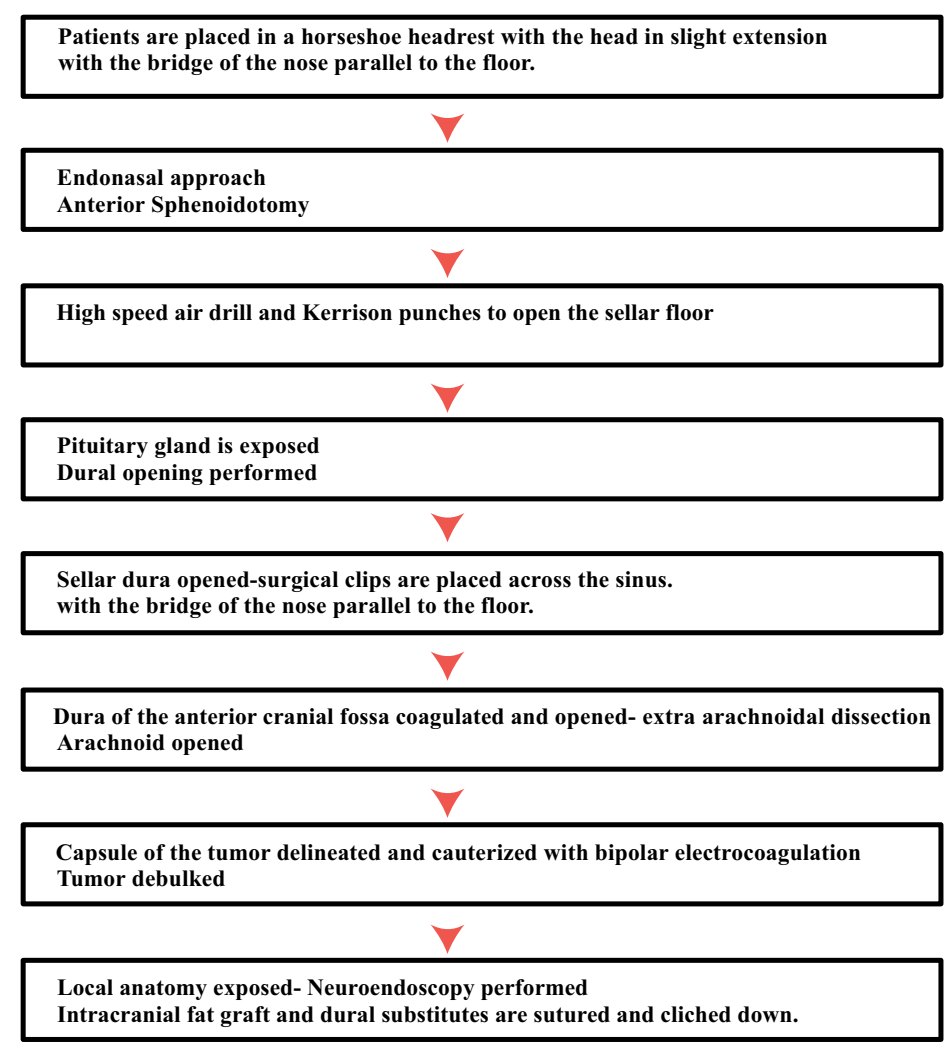

Fig. (3). General EET workflow.

is still an active debate going on the field if the endoscopic surgery should be the preferred mode of operation or not. A general EET procedure is outlined (Fig. 3).

\section{LITERATURE REVIEW}

\subsection{History of Surgical Robots}

The very first US FDA approved robotic system since 1994 is Automated Endoscopic System for Optimal Positioning (AESOP) from Computer Motion Inc (CMI). There was some evidence that AESOP had some benefit, but some limitations were reported $[12,13]$. CMI (Computer Motion Inc.) and SRI (Stanford Research Institute Inter- national) were the two first pioneers in the surgical robot that later in 2004 merged, and the da Vinci system was proposed. Its unique features like 3dimensional visualization, a stable camera, and operating platform, 7 degrees of freedom articulating instruments, comfortable ergonomics, and trembling- free movements, the clinical utilization took the product to the next level [14 - 16]. Because the advantages mentioned above, the da Vinci systems received mostly outstanding positive reviews [17]. However, on its flip side, since the surgical robot is mechanical based, there are some disadvantages associated with it. Da Vinci system lacks feedback sensation or haptic technology and also it is bulky. Because of its bulkiness and lack of haptics system, it might possibly be harmful for the patient under visualization during the surgical procedure [18 - 22]. Programmable Universal Machine for Assembly or PUMA; (Advanced Re-search Robotics, Oxford, CT) was initially designed for holding and manipulating biopsy tools since 1988 [23 - 25]. PUMA is the first robot in neurosurgery that was evident $[26,27]$. In 1989 , Benabid et al. reported the experiment with an early precursor to the robot named NeuroMate (Integrated Surgical Systems, Sacramento, CA) [28, 29]. Concerning a real-time monitoring issue with the image-guided system, Minerva was developed in 1993 from the University of Lausanne, Lausanne, Switzerland. It comprised of a robotic arm placing within a Computed Tomography scanner (CT). The robot allows neurosurgeons to monitor and adjust during the operation in real-time under the proper clinical decision. Subsequently, the US National Aeronautics and Space Administration (NASA; Washington, DC) developed the Robot-Assisted Microsurgery System (RAMS, NASA; Washington, DC) in 1997. This robot could provide a dexterous platform to perform surgery with high precision. In 1999, the SteadyHand was developed at Johns Hopkins University (Baltimore, MD) to be the surgical tool manipulation. The SteadyHand is another dexterity-enhancement system. It was designed to reduce shaking to augment microsurgery. NeuRobot (Shin-shu University School of Medicine, Matsumoto, Japan) was subsequently used to remove a recurrent or atypical meningioma. Table 1 shows an overview of the evolution of surgical robots over time.

\subsection{The Evolution of Robot Assisted Neurosurgery}

Robots are also used in neurosurgery, as they are the right tools for integrating computer technology, medical imaging, and engineering to accomplish the most complicated tasks in the brain and spinal procedures. They are also used during neurosurgery to apply the numerical image explosion and multimodality medical imaging. As outlined in Table 1, few 
Table 1. History of surgical robots.

\begin{tabular}{|c|c|c|c|}
\hline Publication Date & Robot & Application & Investigator \\
\hline 1988 & PUMA 560 & Stereotaxy & Kwoh et al. [33] \\
\hline 1989 & Neuromate & Stereotaxy & Benabid et al. [28] \\
\hline 1991 & PUMA 200 & Retractor & Drake [34] \\
\hline 1993 & Minerva & Stereotaxy & Glauser et al. [35] \\
\hline 1997 & RAMS & Microsurgery & Taylowski et al. [36] [37] \\
\hline 1999 & Steady-Hand & Dexterity Enhancement & Chinzei et al. [38] \\
\hline 2001 & Harvard MR-Compatible & Stereotaxy & Radstzky \& Radolph [39] \\
\hline 2001 & RoboSim & Neurosurgical Simulator & Zimmerman et al. [40] \\
\hline 2002 & Evolution 1 & Stereotaxy, Endoscopy & Ogiwara et al. [44] \\
\hline 2002 & Neurobot & Endoscopy & Louw et al. [41] \\
\hline 2004 & neuroArm & Dexterity Enhancement & Eljamel et al. [42] \\
\hline 2006 & PathFinder & Stereotaxy & Shoham et al. [43] \\
\hline 2007 & Rennaissance & Stereotaxy & Medrobotics Co [31] \\
\hline 2014 & Medrobotics Flex & Stereotaxy, Endoscopy & FDA approved Renaissance robot (Mazor Robotics, Israel) \\
\hline 2016 & Mazor X & Stereotaxy & Globus Medical, Inc (Audubon, PA) \\
\hline 2016 & Excelsius Surgical & Stereotaxy & Ogiwara et al. [31] \\
\hline 2017 & iArmS & Arm-Support robot & \\
\hline
\end{tabular}

other surgical robotic systems are heavily used in the neurosurgery and related spinal applications. The FDA approved Renaissance robot (Mazor Robotics, Israel) is used in brain and spinal surgery. This robot localizes the tool positioning and implant placement. It includes sophisticated software for image guidance, which is ideal for delicate brain and spinal surgery with high accuracy and precision. ROSAR (MEDTECH, France) is another type of robot used for brain and spinal surgery. This particular robot is bulky and comes with an O-ArmR. SurgiScope stereotactic system (Stockholm, Sweden) and MKM microscope system (Carl Zeiss Inc, Germany) are the examples of robots that are integrated within current neurosurgical tools such as the microscope. Cyberknife (Accuray Inc., CA, USA) is also a well-known surgical robot that performs the tumor irradiation not only for the brain tumor but also for other parts of the body with motion tracking [30]. The Medrobotics FlexR Robotic System that was introduced in 1940 is a robotic-assisted transoral surgery tool [31]. Mazor X and Excelsius Surgical system navigate and facilitate access and position to both spine and brain surgery. A smart armsupport robot called iArmSR is another robot that supports neurosurgeon's forearm to prevent from hand trembling and alleviate fatigue during the surgical procedure [32].

\subsection{Design and Development of Neurosurgical Robot- Assisted EET}

The overall goal of this study is to develop the principle of neurosurgical robot-assisted EET to originate the original ideas for the robotic neurosurgical system for EET approach design. This robot would be clinically available with the integrated state of the art technology, e.g., integrated medical imaging (mainly 3D imaging) [45], the computer software and the robot to perform the complete procedure focusing on the transsphenoidal approach. However, Neurosurgeons will still participate in the operation and monitor the whole process while making a critical decision along the entire method. The robot will carry out only at the first stage of the EET approach operation under programmable organization with safety control mode. The tumor or lesion will be taken care with the bleeding control mechanism. After the process is completed, automatically the robot will leave after neurosurgeon decides to finish the operation. The surgical wound will be closed or packed by the assistance. According to this, the robot will achieve the accuracy and precision of navigation system with warranty by the virtual fixture.

\section{CONSIDERED PROCEDURES FOR CONCEPTUAL DESIGN AND DEVELOPMENT}

\subsection{Pre-operative Phase of the Study Design Approach}

One of the critical approaches while developing a robotic surgery is to evaluate individual steps in a particular type of surgery. To address this, Gildenberg proposed a scale popularly known as "the Gildenberg Technology Scale" to classify the efficacy of the surgical robot (Table 2). Four phases include as the following:

Table 2. Definition of the Gildenberg technology scale.

\begin{tabular}{|c|c|}
\hline Phase & Definition \\
\hline 1 & $\begin{array}{c}\text { The device can do what the surgeon can do manually, but not } \\
\text { as efficiently or not as fast. This is of interest only to the } \\
\text { inventor }\end{array}$ \\
\hline 2 & $\begin{array}{l}\text { The device can do what the surgeon does, just as fast and just } \\
\text { as efficiently. This is of interest to the developer and possibly } \\
\text { to potential or actual investors. It may be more useful for } \\
\text { marketing than for surgery. }\end{array}$ \\
\hline 3 & $\begin{array}{l}\text { The device can do what the surgeon does, but faster or better. } \\
\text { This is of interest to other surgeons and to investors, may be } \\
\text { cost effective, and may be used at many institutions. } \\
\text { The device can do something the surgeon cannot do without } \\
\text { the robot. This is disruptive or revolutionary technology, of } \\
\text { interest to all. }\end{array}$ \\
\hline
\end{tabular}

Several criteria need to be satisfied to achieve all the phases of the Gildenberg technology. They are as follows. 
(a) More precise, accurate and faster neurosurgical procedures than a neurosurgeon can perform as usual.

(b) Under the image guidance, the robot needs to be in direct supervision compared to the manual techniques.

(c) The robot needs to be under the direct control of the neurosurgeon.

(d) The robot should be able to execute the procedure that must be operated under the neurosurgeon supervision for the patient safety concern $[31,32]$.

\subsection{EETS Pathway Guidance Surgical Simulator}

Also, as a part of pre-operative study design, a robotassisted EET approach is sought to reach the sellar region via transsphenoidal sinus that is relevant to the Gildenberg technology scale criteria as follows

(a) More precise, accurate and faster neurosurgical procedures than a neurosurgeon can perform as usual.

(b) Compared to the manual technique, this approach is direct, and a neurosurgeon can directly control the robotic functions.

(c) The robot can move and stop at the floor of sellar region precisely under new paradigm navigation and allows the neurosurgeon to make a decision.

Following additional measures must be considered while designing the study.

(a) The EET procedure must be performed under the welltrained neuro- surgeon supervision for the patient safety concern.

(b) Neurosurgeons must have the ability to create an intuitive image of the 3D neurosurgical anatomic image, irrespective of the usage of the endoscope. Previously, several reviews on the neurosurgical robots have been published, but the evidence to support the EET approach robot system that is available to operate a master model is missing [30]. In this current study, we have intended to focus on the tenets of neurosurgical robot-assisted EET approach that are described in detail to originate the original ideas for the robotic neurosurgical system for EET approach design. Seven principles are concluded as followings.

\subsection{Seven Principles of the Neurosurgical Robot-Assisted EET}

(1) The patient safety is paramount.

(2) The workspace determination in EET approach

(3) The safest pathway with the virtual fixture.

(4) The fixed patient position for the robotic-assisted surgery.

(5) The target and trajectory determination.

(6) Mode of action.

(7) The robotic platform.

Concerning these tenets, the ideal EET approach neurosurgical robotic design is obtained (Fig. 4).
The crucial components of the neurosurgical robotic system must comprise of the controller, interface system, and the robot. All the elements must be integrated and appointed under the navigation system or the direct endoscopic visualization. Since the control system is the heart of the robotic- assisted surgery, a high degree of precision is required regarding the delicate and eloquent neuroanatomical structure. This allows neurosurgeons to localize their desired threedimensional position precisely and to coordinate the patient's brain both during the preoperational and the peri-operational phase. A high degree of accuracy is needed for the repetitive positioning of the dis-sectors and the surgical tools. The accuracy and precision of spatial and the real-time approach are the central concepts of the control system. Further, the steady motion of the robot establishes the reliability of the system. By the computerization, the most effective trajectory of the robot to reach the anticipated position and coordination is planned preoperatively. The navigation system creates its path planning. During this step, a pre-designed algorithm is used to determine the preferred and safety workspace of the robot by the neurosurgeon preoperatively. The workspace is the area where the neurosurgeon operates safely. As per the clinical anatomy with neurosurgeons' knowledge, the workspace is designed. As a rule of thumb, the workspace is created after conducting a simulation or cadaveric study under the image guidance techniques. In a typical scenario three different types of the workspace are defined (a). Available workspace: A workspace where a neurosurgeon can access the intranasal anatomical structures (among the nostrils to the skull base area), (b) Target based workspace: where the neurosurgeon operates and aims to approach the target. This workspace is different from the available workspace that at the end of the trajectory-to-target workspace is a pinpoint area at the goal rather than the end of the convenient workspace, and (c) The universal workspace: the entire area of the space for the robot installation.

An anatomical configuration study is very much needed. Current knowledge regarding the anatomical structure relevant to the EET approach is mainly based on post-mortem or imaging studies [46, 47]. Among the imaging techniques, Computerized Tomography (CT) has the potential to examine the basal skull and intranasal structures in several aspects, particularly for preoperative evaluation of the bony parts [48, 49]. Additionally, CT imaging provides greater accuracy and safety for studying skull base anatomy to identify and classify the EET approach workspace [50 - 52].

It is important to note that, before the operation, the viral fixture is created which in principle helps to limit the desired safety workspace preoperatively. In return, this feature guarantees the patient safety during the operation by the robot, which is planned and simulated by the neurosurgeons for preoperative determination, particularly for the patient safety. The robotic platform systems are crucial in the robotic system for EET approach. The parallel platform (a type of the robotic platform) is the superior compared to the serial link robotic arm. Because of stiffness, accuracy and high-speed operation, the parallel platform is recommended to be the primary underlying design for this EET approach neurosurgical robot. 


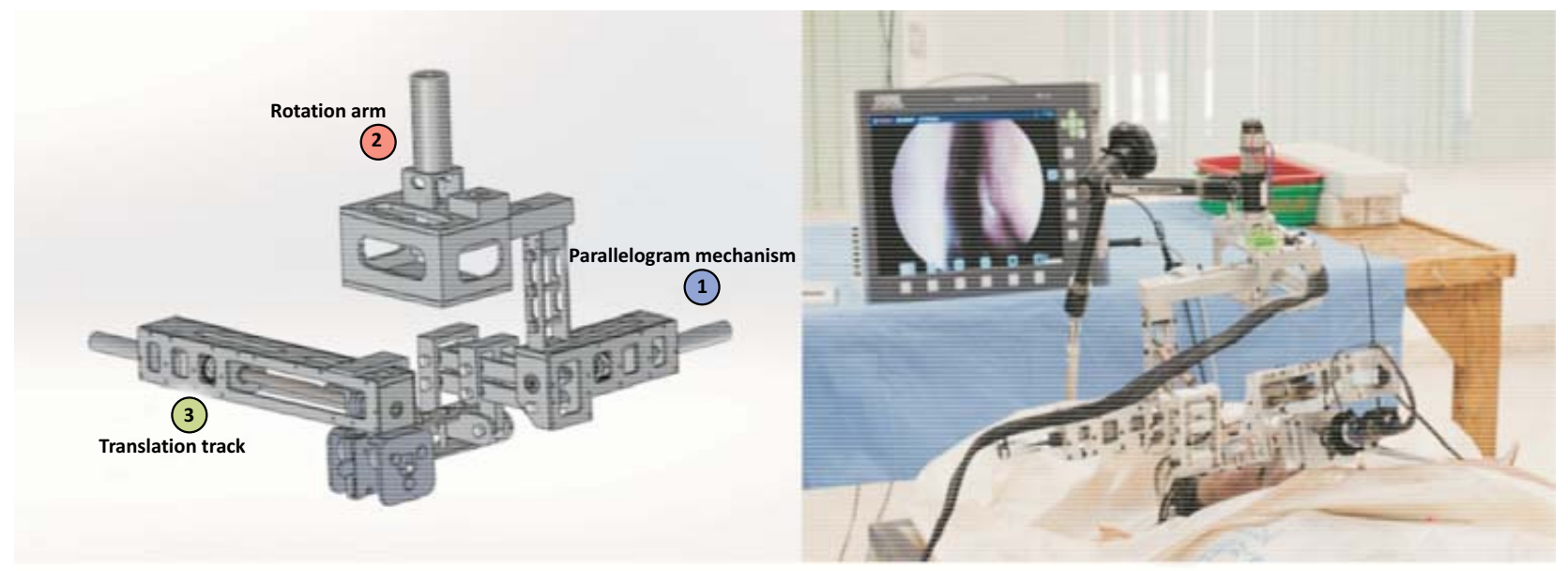

(a)

(b)

Fig. (4). The illustration depicts the neurosurgical robot prototype with respect to seven tenets (a) 3D View of the robot CAD design (b) the robot during the experiment.

It is also crucial to assign a mode of action while designing a neurosurgical robot. The tele-presence mode is required [53 56], as the robot needs to be in a standalone version under control by a neurosurgeon. The independent method is essential as the neurosurgeon is able to operate the patient remotely using specialized tools. Among the separate action and at the desired position and coordination, the neurosurgeon will take care of the entire procedure to accomplish the operation.

The overall goal is to design a robot that can execute a minimally invasive trans-sphenoidal approach. However, it is also essential to keep the technical feasibility in mind that may or may not result in the complete desired robotic model. During the Preoperative phase, at the first step, the desired coordination and position of sellar region is achieved under the navigation system by a neurosurgeon. This helps the robotic software system to calculate the distance and trajectory-totarget workspace within the brain whether to reach the sellar turcica or around the anterior cranial fossa. Next, a virtual fixture is created, which limit the safety boundary for the neurosurgeon. Nostril is identified once, the patient is positioned, and then the cylindrical robotic arm is inserted under automatic mode.

The endoscope, suction, and dissectors are then packed into the working channel, which then assembles into the cylindrical robotic arm to reach the deepest point of the nose. This action is followed by automatic identification of the opening of the sphenoid sinus under the navigation system. Once the dissection is completed, breaking the compressible of vomer opens the sphenoid sinus, which allows targeting the sphenoid sinus. The overall measurement between the orifice and the incision site to the vomer is calculated under the navigation system. The robotic arm in the operative field is controlled in the teleoperation control mode to operate on the trajectory under navigation system. For the safety reason, the virtual fixture and the image based guidance limit the boundary of the operative field. Once the neurosurgeon decides to finish the operation, bleeding flow is evaluated, and the instruments are then positioned safely away from the patient. Surgical assistants complete the intranasal packing, and the step concludes the operation.

\section{EXPERIMENTS AND RESULTS}

This research presents a new robotic system to assist in normal procedure of EETS as shown in Fig. (4). A real-time $3 \mathrm{D}$ navigation system is used in this proposed system, which is based on imaging technique with optical tracking occurring in the period before a surgical operation. The tracking system is used to develop a virtual endoscopy along with the surgical tool and provides a 3D model of the bone structure. The bone anatomy $3 \mathrm{D}$ model in the workspace is created by using CT pre-operative images [57]. The real-time surgical tool navigation along with virtual endoscope is provided by the optical tracking system along with the 3D model.

To estimate and collect the position of the tool movement during surgery, optical markers are attached with the surgical tools and computed using MATLAB program. The workspace and the motion behaviour of surgical tools can be easily calculated using the collected motion data. Using a homogeneous transformation, the tool's position can be calculated from the marker to the tool tip [58]. The position and orientation data of the object attached with the optical marker is recorded in 3-dimension. The commercial optical tracking system, Polaris ${ }^{\circledR} \mathrm{S}$ Vicra ${ }^{\circledR}$ system from Northern Digital Inc. is used during the experiment shown in Fig. (5). The horizontal plane was represented by using another optical tracking system. Controlling algorithm is interfaced with the joystick. MATLAB Programming was used to record instrument motion during experiments.

The remote centre of motion at nostril entrance must generate to create a mechanical constraint of the surgery. The experiment was executed to confirm that the tool moved with the constraint at the remote centre of motion point and also the position of the surgical tool tip located at the phantom nostril entrance. The 3D plot (Fig. 6) represents the tool movement during the experiment time. While the red circle represents the medical tool tip, yellow circle performs as a centre of motion point. 

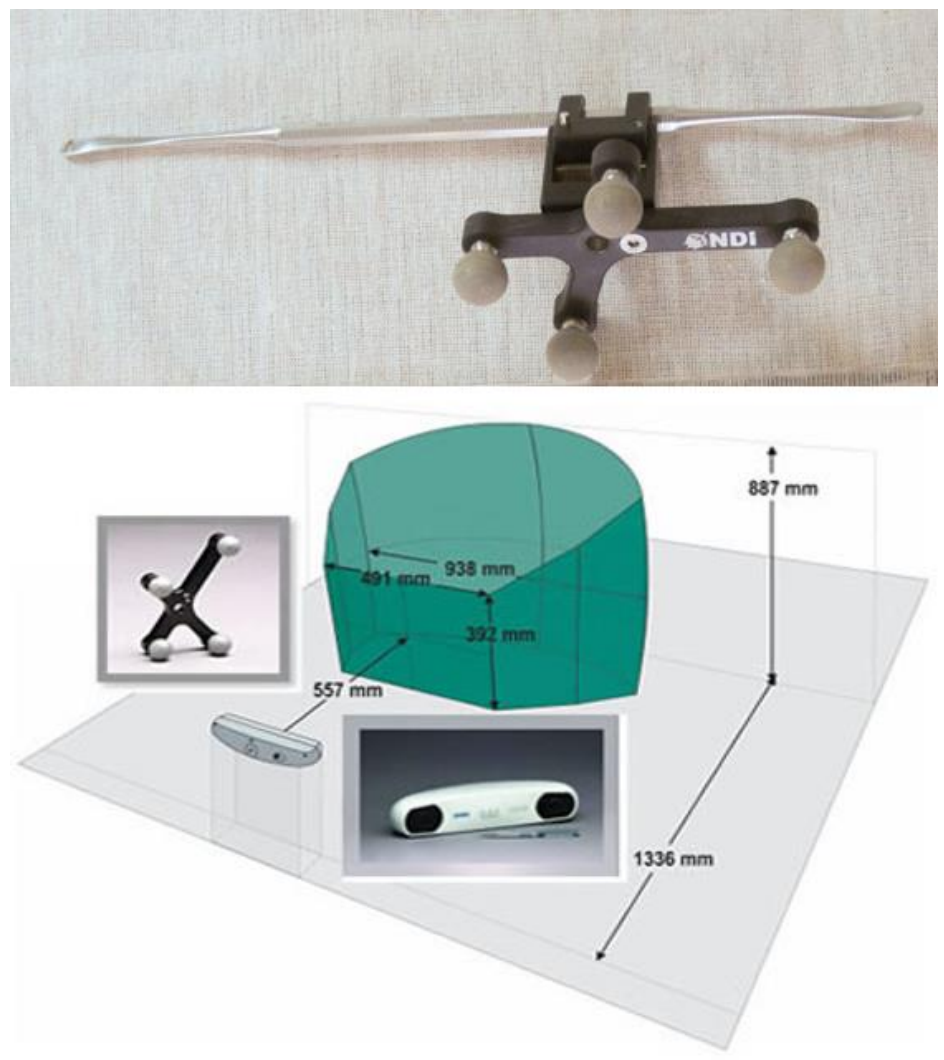

Fig. (5). Surgical tool attached with optical marker.

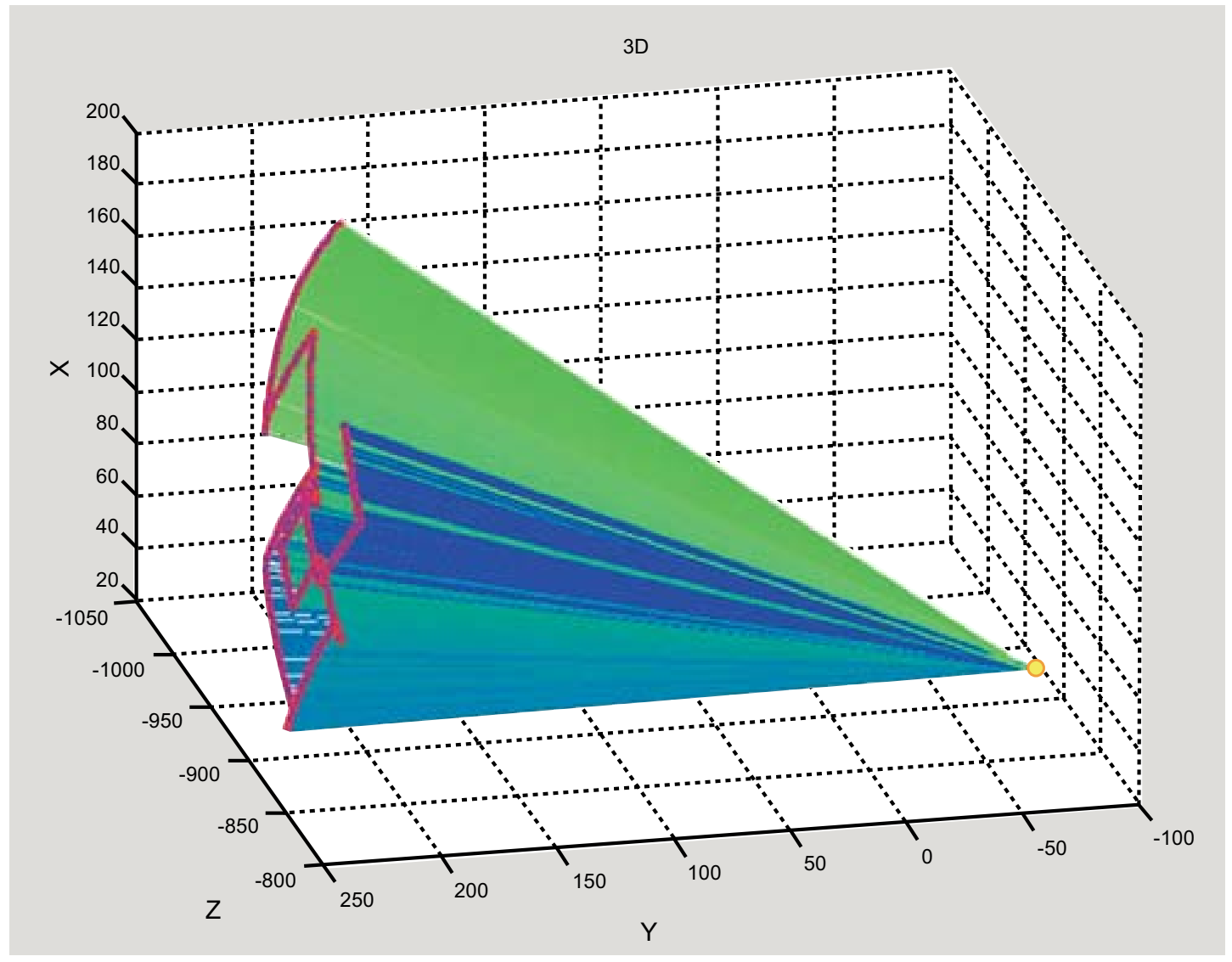

Fig. (6). Robot motion with tool tip at the RCM point. 


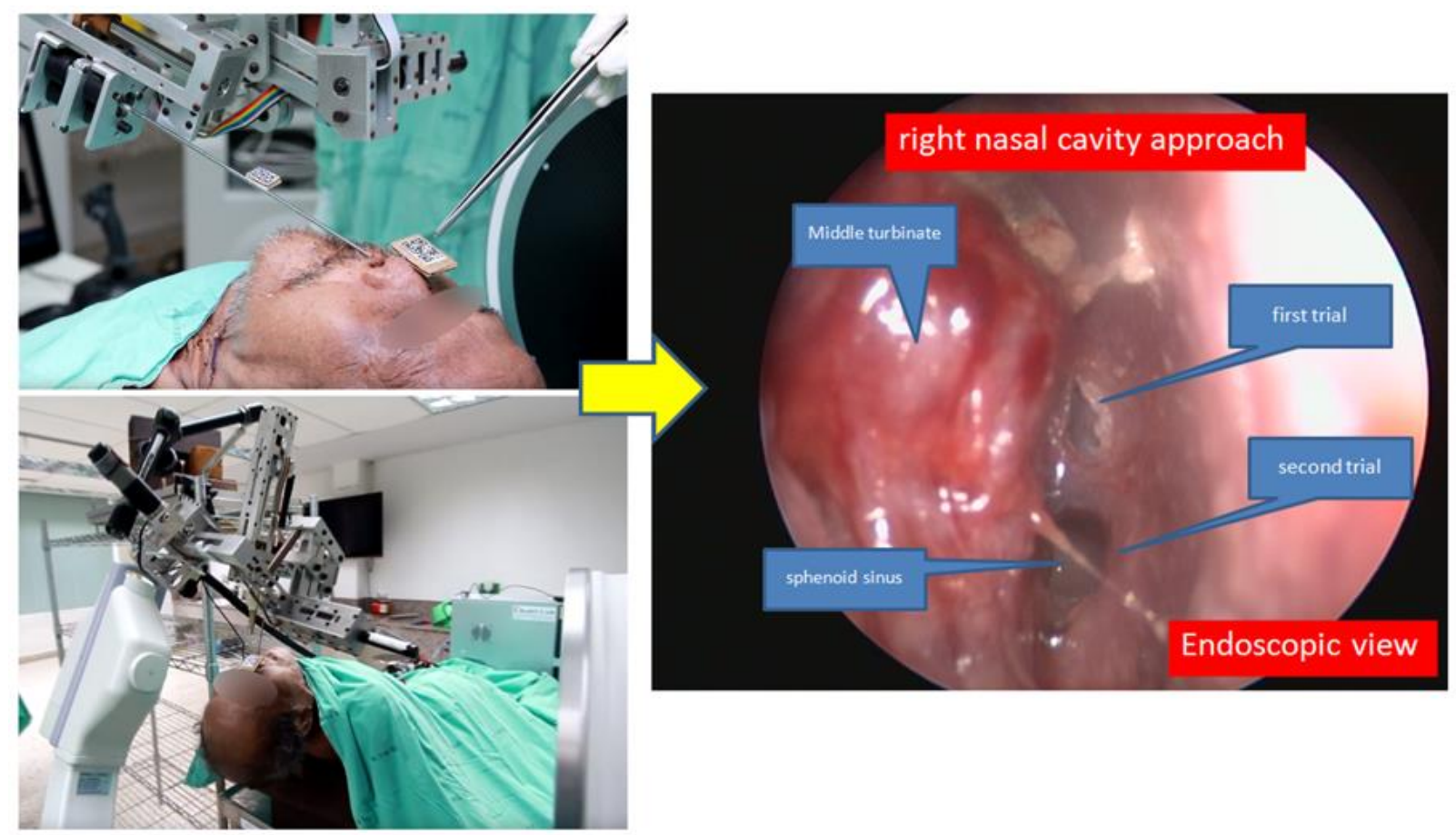

Fig. (7). BART LAB EETS robotic platform in cadaveric experiment.

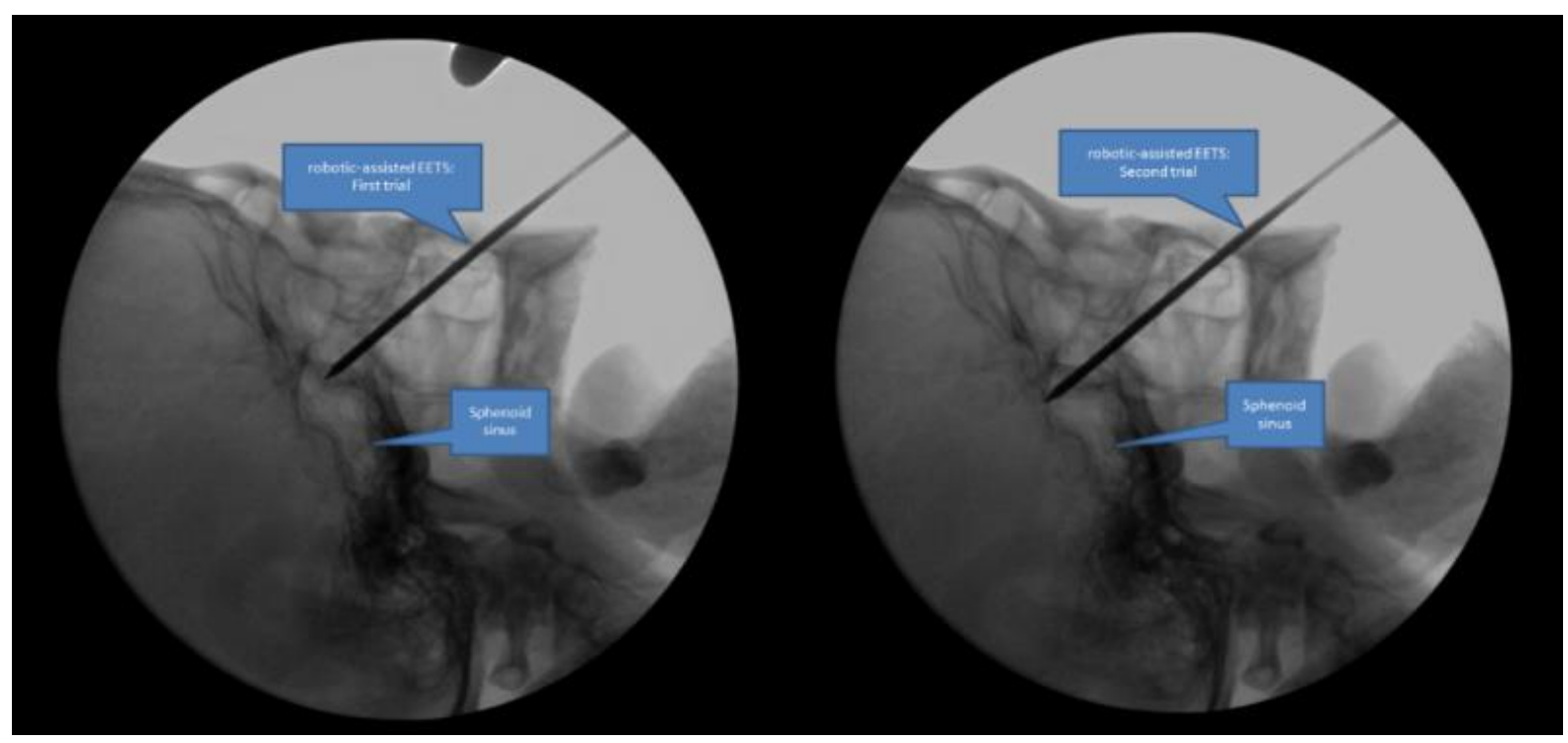

Fig. (8). Lateral fluoroscopic view of the first and second trial depicted robot reached to the desired target (sphenoid sinus).

From the result, the robot can perform tool movement under the constraint at the tool tip and yield the remote center of motion movement. To accumulate the tool movements during EETS a human cadaver-based experiment was conducted shown in Fig. (7). The control mode was telesurgical system which is using real time image from the surgical scene for neurosurgeon to make decision during the operation. Neurosurgeon can control the robot on-line. The advantages are fast and simple manual but the setup time perioperatively would be longer than conventional technique. Eventually, this is the first document of the robotic-assisted EETS with optical tracking and fluoroscopic guidance. There were two trials during the robot assisted surgery which were satisfied to target at the sphenoid sinus as Fig. (8). 


\section{DISCUSSION}

\subsection{The Brighter Side of the Coin}

Neurosurgical Robotic technology is in demand and blooming. From the out- line made above it is now clear that robot-assisted neurosurgical operations have advantages in the overall surgical procedures. This includes but is not limited to the catheter guidance, global navigation, and the intraoperative imaging. The booming technology allows increased safety not only to the patients but also to the neurosurgeons. Also, it offers augmented operative control and consistency in action to the neurosurgeons. Robotic engineering in neurosurgical procedure has benefits in both ends: at the patient end, it incorporates force measurements and offers a real-time response that helps in preventing vessel puncture and damage to delicate structures during the operation, while on the other hand it benefits surgeons and offers to work remotely while staying away from the radiation sources. This engineering also provides improved stability in remedial actions and greater freedom of motion. Because of the enhanced surgical precision and resistance to fatigue, robotic technologies provide a platform with improved ability to minimize incisions and surgical errors in the brain and spinal surgery.

\subsection{The Darker Side of the Coin}

The substitution or addition of robots into neurosurgical practice comes with potential complications, as the brain is delicate. Also, the entire manufacturing process (research and development cost and post-manufacture maintenance) is costeffective and time-consuming. To achieve this ambitious goal a widespread incorporation is required along with a decent investment overall. Another important consideration while thinking of surgical robots is the disruption of on- going workflow. Introduction of robotic technology has the potential to change the overall dynamic of the existing operating room and adequate flow. This is particularly not feasible during emergency situations. When we think of robotic assistance surgical procedures, it involves a month's extended training of both surgeons and surgical support staff on its usage. This not only requires a significant amount of time but also requires a steep learning curve and frequent practice for the refinement of surgical skills of the staff. As mentioned above, the surgical robots offer to work remotely while staying away from the radiation sources. However, on its flip side, it is time efficient especially during the transition to open surgery. This has a potential for deleterious post-surgical impact on the patient.

\subsection{Future Perspectives}

Robotic applications to neurosurgery are still in their early stage and need more work to get into the flow. With time, as the overall engineering process (design, development, and test) improves, till that several relevant factors must be considered as discussed above before executing the machine. It is very crucial to have a balance between surgeon mediated operational control and robotic autonomy. This is particularly important for the overall safety, utilization, and adaptation to the changing surgical conditions inside the operative room. There is no doubt that an efficient robotic system offers an increased precision in the surgical procedure, but at the same time, they lack the factors necessary for the crucial surgical decisions such as training, experience, and human judgment. Regardless, adaptation to the neurosurgical robotic technology for the neurosurgical interventions displays the most promise for increasing clinical implementation. Overall, we believe that adaption to surgical robots into real neurosurgical practice will take it to the next level.

\section{CONCLUSION}

Robotic technology, particularly in neurosurgical practices, opens a door for broader clinical use. The growing technologies can envision a potential for robotics to make meaningful impacts in the field of neurosurgery. However, at its present, more investigation, more in-depth research and greater collabo- ration between various interventional areas are required to move forward with this blooming technology.

\section{CONSENT FOR PUBLICATION}

Not applicable.

\section{STANDARD OF REPORTING}

PRISMA Guideline and methodology were followed.

\section{FUNDING}

The study is funded by Health Systems Research Institute of Thailand (HSRI), Grant No. 57-025.

\section{CONFLICT OF INTEREST}

The authors declare no conflict of interest, financial or otherwise.

\section{ACKNOWLEDGEMENTS}

Authors would like to express their gratitude to Health Systems Research Institute of Thailand (HSRI).

\section{REFERENCES}

[1] Cai F, Lu W, Shi W, He S. A mobile device-based imaging spectrometer for environmental monitoring by attaching a lightweight small module to a commercial digital camera. Sci Rep 2017; 7(1): 15602 .

[http://dx.doi.org/10.1038/s41598-017-15848-x] [PMID: 29142283]

[2] He L, Ming X, Liu Q. A medical application integrating remote 3D visualization tools to access picture archiving and communication system on mobile devices. J Med Syst 2014; 38(4): 44.

[http://dx.doi.org/10.1007/s10916-014-0044-y] [PMID: 24705800]

[3] Wu PY, Cheng CW, Kaddi CD, Venugopalan J, Hoffman R, Wang MD. -Omic and electronic health record big data analytics for precision medicine. IEEE Trans Biomed Eng 2017; 64(2): 263-73. [http://dx.doi.org/10.1109/TBME.2016.2573285] [PMID: 27740470]

[4] Nathoo N, Cavuşoğlu MC, Vogelbaum MA, Barnett GH. In touch with robotics: Neurosurgery for the future. Neurosurgery 2005; 56(3): 421-33.

[http://dx.doi.org/10.1227/01.NEU.0000153929.68024.CF] [PMID: 15730567]

[5] Smith WD, Berguer R, Forkey DL. Virtual ergonomic studies in endoscopic intervention. Adm Radiol J 1998; 17(11): 21-3. [PMID: 10345003]

[6] Berguer R, Forkey DL, Smith WD. Ergonomic problems associated with laparoscopic surgery. Surg Endosc 1999; 13(5): 466-8. [http://dx.doi.org/10.1007/PL00009635] [PMID: 10227943]

[7] Berguer R, Chen CY, Smith WD. A virtual instrument ergonomics workstation to measure surgeons' physical stress. Stud Health Technol Inform 1999; 62: 49-54. [PMID: 10538398] 
[8] Berguer R. Surgery and ergonomics. Arch Surg 1999; 134(9): 1011-6. [http://dx.doi.org/10.1001/archsurg.134.9.1011] [PMID: 10487599]

[9] Huettner F, Dynda D, Ryan M, Doubet J, Crawford DL. Roboticassisted minimally invasive surgery; A useful tool in resident training-the Peoria experience, 2002-2009. Int J Med Robot 2010; 6(4): 386-93.

[http://dx.doi.org/10.1002/rcs.342] [PMID: 20687050]

[10] Bandoh T, Shiraishi N, Yamashita Y, et al. Endoscopic surgery in Japan: The 12th national survey(2012-2013) by the Japan Society for Endoscopic Surgery. Asian J Endosc Surg 2017; 10(4): 345-53. [http://dx.doi.org/10.1111/ases.12428] [PMID: 28980441]

[11] Mortini P. Cons: Endoscopic endonasal transsphenoidal pituitary surgery is not superior to microscopic transsphenoidal surgery for pituitary adenomas. Endocrine 2014; 47(2): 415-20. [http://dx.doi.org/10.1007/s12020-014-0365-0] [PMID: 25081297]

[12] Mettler L, Ibrahim M, Jonat W. One year of experience working with the aid of a robotic assistant (the voice-controlled optic holder AESOP) in gynaecological endoscopic surgery. Hum Reprod 1998; 13(1O): 2748-50.

[http://dx.doi.org/10.1093/humrep/13.10.2748] [PMID: 9804224]

[13] Mohr FW, Onnasch JF, Falk V, Walther T, Diegeler A, Krakor R. The evolution of minimally invasive valve surgery- 2 year experience. Eur J Cardiothorac Surg 1999; 15: 233-238-9.

[14] Giulianotti PC, Coratti A, Angelini M, et al. Robotics in general surgery: Personal experience in a large community hospital. Arch Surg 2003; 138(7): 777-84.

[http://dx.doi.org/10.1001/archsurg.138.7.777] [PMID: 12860761]

[15] Box GN, Ahlering TE. Robotic radical prostatectomy: Long-term outcomes. Curr Opin Urol 2008; 18(2): 173-9.

[http://dx.doi.org/10.1097/MOU.0b013e3282f517d6] [PMID: 18303539]

[16] Hanna EY, Holsinger C, DeMonte F, Kupferman M. Robotic endoscopic surgery of the skull base: A novel surgical approach. Arch Otolaryngol Head Neck Surg 2007; 133(12): 1209-14.

[http://dx.doi.org/10.1001/archotol.133.12.1209] [PMID: 18086961]

[17] Giuseppe T, Tommaso R, Iris De F, Paolo D, Arianna MA. Miniature Robot for Retraction Tasks under Vision Assistance in Minimally Invasive Surgery. Robotics 2014; 3: 70-82.

[http://dx.doi.org/10.3390/robotics3010070]

[18] Gori M, Sciutti A, Burr D, Sandini G. Direct and indirect haptic calibration of visual size judgments. PLoS One 2011; 6(10)e25599 [http://dx.doi.org/10.1371/journal.pone.0025599] [PMID: 22022420]

[19] Wedmid A, Llukani E, Lee DI. Future perspectives in robotic surgery. BJU Int 2011; 108(6 Pt 2): 1028-36.

[http://dx.doi.org/10.1111/j.1464-410X.2011.10458.x] [PMID: 21917107]

[20] Akinbiyi T, Reiley CE, Saha S, et al. Dynamic augmented reality for sensory substitution in robot-assisted surgical systems. Conf Proc IEEE Eng Med Biol Soc 2006; 1: 567-70.

[http://dx.doi.org/10.1109/IEMBS.2006.259707] [PMID: 17945986]

[21] Tavakoli M, Aziminejad A, Patel RV. Tool/tissue interac- tion feedback modalities in robot-assisted lump localization. Conference Pro- ceeding in IEEE Engineering in Medicine and Biology Society 2006; $1: 3854-7$.

[22] Cruces RA, Wahrburg J. Improving robot arm control for safe and robust haptic cooperation in orthopaedic procedures. Int J Med Robot 2007; 3(4): 316-22.

[http://dx.doi.org/10.1002/rcs.156] [PMID: 17948919]

[23] Nathoo N, Cavuşoğlu MC, Vogelbaum MA, Barnett GH. In touch with robotics: Neurosurgery for the future. Neurosurgery 2005; 56(3): 421-33.

[http://dx.doi.org/10.1227/01.NEU.0000153929.68024.CF] [PMID: 15730567]

[24] Zamorano L, Li Q, Jain S, Kaur G. Robotics in neurosurgery: State of the art and future technological challenges. Int J Med Robot 2004; 1(1): 7-22.

[http://dx.doi.org/10.1002/rcs.2] [PMID: 17520593]

[25] Holly LT. Neurosurgical robotics. Int J Med Robot 2006; 2(2): 105-6. [http://dx.doi.org/10.1002/rcs.93] [PMID: 17520620]

[26] Davies B. A review of robotics in surgery. Proc Inst Mech Eng H 2000; 214(1): 129-40.

[http://dx.doi.org/10.1243/0954411001535309] [PMID: 10718057]

[27] Elder JB, Hoh DJ, Oh BC, Heller AC, Liu CY, Apuzzo ML. The future of cerebral surgery: A kaleidoscope of opportunities. Neurosurgery 2008; 62(6)(Suppl. 3): 1555-79.

[http://dx.doi.org/10.1227/01.neu.0000333820.33143.0d] [PMID: 18695575]
[28] Benabid AL, Hoffmann D, Lavallee S, et al. Is there any future for robots in neurosurgery? Adv Tech Stand Neurosurg 1991; 18: 3-45. [http://dx.doi.org/10.1007/978-3-7091-6697-0_1] [PMID: 1930374]

[29] Benabid AL. A routine stereotactic procedure in 2003. Neurosurgery 1993; 33(4): 660-2.

[PMID: 8232806]

[30] Niranjan A, Lunsford LD. Radiosurgery: Where we were, are, and may be in the third millennium. Neurosurgery 2000; 46(3): 531-43. [http://dx.doi.org/10.1097/00006123-200003000-00002] [PMID: 10719848]

[31] Ogiwara T, Goto T, Nagm A, Hongo K. Endoscopic endonasal transsphenoidal surgery using the iArmS operation support robot: Initial experience in 43 patients. Neurosurg Focus 2017; 42(5)E10 [http://dx.doi.org/10.3171/2017.3.FOCUS16498] [PMID: 28463614]

[32] Newsome H, Mandapathil M, Koh YW, Duvvuri U. Utility of the highly articulated flex robotic system for head and neck procedures: A cadaveric study. Ann Otol Rhinol Laryngol 2016; 125(9): 758-63. [http://dx.doi.org/10.1177/0003489416653409] [PMID: 27287677]

[33] Kwoh YS, Hou J, Jonckheere EA, Hayati S. A robot with improved absolute positioning accuracy for $\mathrm{CT}$ guided stereotactic brain surgery. IEEE Trans Biomed Eng 1988; 35(2): 153-60. [http://dx.doi.org/10.1109/10.1354] [PMID: 3280462]

[34] Drake AG. Dispelling dog dogma: An investigation of heterochrony in dogs using 3D geometric morphometric analysis of skull shape. Evol Dev 2011; 13(2): 204-13.

[http://dx.doi.org/10.1111/j.1525-142X.2011.00470.x] [PMID: 21410876]

[35] Glauser G, Flury P, Epitauz M, Piquet Y, Burckhardt C. Neurosurgical operation with the dedicated robot minerva. IEEE EMBS 1993; pp. 347-51.

[36] Kozlowski DM, Morimoto AK, Charles ST. Micro-telerobotic surgical system for microsurgery. Stud Health Technol Inform 1997; 39: 216-23.

[PMID: 10168916]

[37] Taylor RH, Jensen P, Whitcomb L, et al. A steady-hand robotic system for microsurgical augmentation.Medical Image Computing and Computer- Assisted Interventions. Cambridge: Springer 1999.

[http://dx.doi.org/10.1007/10704282_112]

[38] Chinzei K, Miller K. Towards MRI guided surgical manipulator. Med Sci Monit 2001; 7(1): 153-63.

[PMID: 11208513]

[39] Radetzky A, Rudolph M. Simulating tumour removal in neurosurgery. Int J Med Inform 2001; 64(2-3): 461-72. [http://dx.doi.org/10.1016/S1386-5056(01)00197-6] 11734406]

[40] Zimmermann M, Krishnan R, Raabe A, Seifert V. Robot-assisted navigated neuroendoscopy. Neurosurgery 2002; 51(6): 1446-51. [http://dx.doi.org/10.1097/00006123-200212000-00015] [PMID: 12445350]

[41] Louw DF, Fielding T, McBeth PB, Gregoris D, Newhook P, Sutherland GR. Surgical robotics: A review and neurosurgical prototype development. Neurosurgery 2004; 54(3): 525-36. [http://dx.doi.org/10.1227/01.NEU.0000108638.05274.E9] [PMID: 15028126]

[42] Eljamel MS. Robotic application in epilepsy surgery. Int J Med Robot 2006; 2(3): 233-7.

[http://dx.doi.org/10.1002/rcs.97] [PMID: 17520637]

[43] Shoham M, Lieberman IH, Benzel EC, et al. Robotic assisted spinal surgery--from concept to clinical practice. Comput Aided Surg 2007; 12(2): $105-15$.

[PMID: 17487660]

[44] Ogiwara H, Uematsu K, Morota N. Obliteration of the choroid plexus after endoscopic coagulation. J Neurosurg Pediatr 2014; 14(3): 230-3. [http://dx.doi.org/10.3171/2014.6.PEDS1438] [PMID: 24995821]

[45] Mudunuri AV. Autonomous camera control system for surgical robots. 2011.

[46] Cavallo LM, Messina A, Cappabianca P, et al. Endoscopic endonasal surgery of the midline skull base: Anatomical study and clinical considerations. Neurosurg Focus 2005; 19(1)E2

[http://dx.doi.org/10.3171/foc.2005.19.1.3] [PMID: 16078816]

[47] García-Garrigós E, Arenas-Jiménez JJ, Monjas-Cánovas I, et al. Transsphenoidal approach in endoscopic endonasal surgery for skull base lesions: What radiologists and surgeons need to know. Radiographics 2015; 35(4): 1170-85.

[http://dx.doi.org/10.1148/rg.2015140105] [PMID: 26046941]

[48] Başak S, Karaman CZ, Akdilli A, Mutlu C, Odabaşi O, Erpek G. Evaluation of some important anatomical variations and dangerous 
areas of the paranasal sinuses by CT for safer endonasal surgery. Rhinology 1998; 36(4): 162-7.

[PMID: 9923058]

[49] Mylonas N, Damianou C. MR compatible positioning device for guiding a focused ultrasound system for the treatment of brain deseases. Int J Med Robot 2014; 10(1): 1-10.

[http://dx.doi.org/10.1002/rcs.1501] [PMID: 23744569]

[50] Abolhassani N, Jung S, Okamura AM, Judkins TN. Augmented reality and haptic interfaces for robot-assisted surgery. Int J Med Robot 2012; 8: $45-56$.

[http://dx.doi.org/10.1002/rcs.421]

[51] Bly RA, Su D, Lendvay TS, et al. Multiportal robotic access to the anterior cranial fossa: A surgical and engineering feasibility study. Otolaryngol Head Neck Surg 2013; 149(6): 940-6.

[http://dx.doi.org/10.1177/0194599813509587] [PMID: 24154747]

[52] Bekeny JR, Swaney PJ, Webster RJ III, Russell PT, Weaver KD.

Forces applied at the skull base during transnasal endoscopic transsphenoidal pituitary tumor excision. J Neurol Surg B Skull Base 2013; 74(6): 337-41.

[http://dx.doi.org/10.1055/s-0033-1345108] [PMID: 24436934]

[53] Chen Z, Deguet A, Taylor R, DiMaio S, Fischer G, Kazanzides P. An open-source hardware and software Platform for telesurgical robotics research. Proceedings of the MICCAI Workshop on Systems and Architecture for Computer Assisted Interventions. Nagoya, Japan. 2013.

[54] Lum MJ, Friedman DC, Sankaranarayanan G, et al. The RAVEN Design and validation of a telesurgery system. Int J Robot Res 2009; 28: 1183-97.

[http://dx.doi.org/10.1177/0278364909101795]

[55] Zhu D, Gedeon T, Taylor K. "Moving to the centre": A gaze-driven remote camera control for teleoperation. Interact Comput 2011; 23: 85-95.

[http://dx.doi.org/10.1016/j.intcom.2010.10.003]

[56] Dragan A, Lee KCT, Srinivasa S. Teleoperation with intelligent and customizable interfaces. J Hum Robot Interact 2013; 2: 33-79.

[57] Emeagwali I, Marayong P, Abbott JJ, Allison M. Okamura. Performance analysis of steady-hand teleoperation versus cooperative manipulation. Proc IEEE Haptics. 1-7.

[58] Suratriyanont N, Suthakorn J. 3D navigation for transsphenoidal surgical robotics system based on CT - images and basic geometric approach. Proc IEEE ROBIO. 2007-12.

[http://dx.doi.org/10.1109/ROBIO.2013.6739764]

\section{(C) 2019 Chumnanvej et al.}

This is an open access article distributed under the terms of the Creative Commons Attribution 4.0 International Public License (CC-BY 4.0), a copy of which is available at: https://creativecommons.org/licenses/by/4.0/legalcode. This license permits unrestricted use, distribution, and reproduction in any medium, provided the original author and source are credited. 